\title{
Um breve histórico da psicologia jurídica no Brasil e seus campos de atuação
}

\author{
A brief history of forensic psychology in \\ Brazil and its fields of application
}

\author{
Vivian de Medeiros LAGO' \\ Paloma AMATO \\ Patrícia Alves TEIXEIRA \\ Sonia Liane Reichert ROVINSKI ${ }^{2}$ \\ Denise Ruschel BANDEIRA
}

\begin{abstract}
Resumo
Este artigo tem como objetivo discutir alguns referenciais históricos da Psicologia Jurídica no Brasil e, a seguir, apresentar os principais campos de atuação, com uma sucinta descrição das tarefas desempenhadas pelo psicólogo em cada um deles. Um segundo objetivo é que esse material sirva como referencial teórico para disciplinas de Psicologia Jurídica, pois foi delineado para ter um caráter introdutório. As principais áreas de interface entre Psicologia e Direito discutidas são: Direito da Família, Direito da Criança e Adolescente, Direito Cível, Direito Penal e Direito do Trabalho. Questões referentes à formação acadêmica são levantadas e novas possibilidades de atuação na área da Psicologia Jurídica são apontadas, indicando perspectivas futuras sobre o assunto.
\end{abstract}

Unitermos: Psicologia forense. Histórico. Psicólogos.

\begin{abstract}
This article aims to discuss some historical references concerning Forensic Psychology in Brazil and to present the main fields of application and a brief description of the tasks developed by the psychologist in each one. A second aim is for this material to be used as a theoretical reference for Forensic Psychology subjects, since it was designed with this introductory emphasis. The main areas of interface between Psychology and Law are: Family Law, Child and Adolescent Law, Civil Law, Criminal Law and Labor Legislation. Questions related to education are highlighted and new possibilities for working in Forensic Psychology are noted, with a recommendation of future perspectives on the topic.
\end{abstract}

Uniterms: Forensic Psychology. History. Psychologists.

Delimitar o início da Psicologia Jurídica no Brasil é uma tarefa complexa, em razão de não existir um único marco histórico que defina esse momento. Assim, o objetivo deste artigo é apresentar e discutir alguns referenciais históricos documentados que permitam relatar como a Psicologia e o Direito se aproximaram

\section{पVV}

- Universidade Federal do Rio Grande do Sul. Instituto de Psicologia, Programa de Pós-Graduação em Psicologia. R. Ramiro Barcelos, 2600, Sala 120, Santana, 90035-003, Porto Alegre, RS, Brasil. Correspondência para/Correspondence to: D.R. Bandeira. E-mail: <drbandei@terra.com.br>.

2 Tribunal de Justiça do Rio Grande do Sul. Porto Alegre, RS, Brasil. 
na história brasileira. A seguir, serão apresentados os principais campos de atuação do psicólogo jurídico, com uma sucinta descrição das tarefas desempenhadas em cada setor. Objetiva-se, ainda, que o artigo possa ser utilizado como referência bibliográfica para disciplinas de Psicologia Jurídica, pois seu caráter introdutório foi delineado com esse propósito.

A história da atuação de psicólogos brasileiros na área da Psicologia Jurídica tem seu início no reconhecimento da profissão, na década de 1960. Tal inserção deu-se de forma gradual e lenta, muitas vezes de maneira informal, por meio de trabalhos voluntários. Os primeiros trabalhos ocorreram na área criminal, enfocando estudos acerca de adultos criminosos e adolescentes infratores da lei (Rovinski, 2002). O trabalho do psicólogo junto ao sistema penitenciário existe, ainda que não oficialmente, em alguns estados brasileiros há pelo menos 40 anos. Contudo, foi a partir da promulgação da Lei de Execução Penal (Lei Federal no 7.210/84) Brasil (1984), que o psicólogo passou a ser reconhecido legalmente pela instituição penitenciária (Fernandes, 1998).

Entretanto, a história revela que essa preocupação com a avaliação do criminoso, principalmente quando se trata de um doente mental delinquente, é bem anterior à década de 1960 do século XX. Durante a Antiguidade e a Idade Média a loucura era um fenômeno bastante privado. Ao "louco" era permitido circular com certa liberdade, e os atendimentos médicos restringiam-se a uns poucos abastados. A partir de meados do século XVII, a loucura passou a ser caracterizada por uma necessidade de exclusão dos doentes mentais. Criaram-se estabelecimentos para internação em toda a Europa, nos quais eram encerrados indivíduos que ameaçassem a ordem da razão e da moral da sociedade (Rovinski, 1998). A partir do século XVIII, na França, Pinel realizou a revolução institucional, liberando os doentes de suas cadeias e dando assistência médica a esses seres segregados da vida em sociedade (Pavon, 1997).

Após esse período, os psicólogos clínicos começaram a colaborar com os psiquiatras nos exames psicológicos legais e em sistemas de justiça juvenil (Jesus, 2001). Com o advento da Psicanálise, a abordagem frente à doença mental passou a valorizar o sujeito de forma mais compreensiva e com um enfoque dinâmico. Como 484 consequência, o psicodiagnóstico ganhou força, deixan- do de lado um enfoque eminentemente médico para incluir aspectos psicológicos (Cunha, 1993). Os pacientes passaram a ser classificados em duas grandes categorias: de maior ou de menor severidade, ficando o psicodiagnóstico a serviço do último grupo, inicialmente. Desta forma, os pacientes menos severos eram encaminhados aos psicólogos, para que esses profissionais buscassem uma compreensão mais descritiva de sua personalidade. Os pacientes de maior severidade, com possibilidade de internação, eram encaminhados aos psiquiatras (Rovinski, 1998). Balu (1984) demonstrou, a partir de estudos comparativos e representativos, que os diagnósticos de Psicologia Forense podiam ser melhores que os dos psiquiatras (Souza, 1998).

De acordo com Brito (2005), os psicodiagnósticos eram vistos como instrumentos que forneciam dados matematicamente comprováveis para a orientação dos operadores do Direito. Inicialmente, a Psicologia era identificada como uma prática voltada para a realização de exames e avaliações, buscando identificações por meio de diagnósticos. Essa época, marcada pela inauguração do uso dos testes psicológicos, fez com que o psicólogo fosse visto como um testólogo, como na verdade o foi na primeira metade do século XX (Gromth-Marnat, 1999). Psicólogos da Alemanha e França desenvolveram trabalhos empírico-experimentais sobre o testemunho e sua participação nos processos judiciais. Estudos acerca dos sistemas de interrogatório, os fatos delitivos, a detecção de falsos testemunhos, as amnésias simuladas e os testemunhos de crianças impulsionaram a ascensão da então denominada Psicologia do Testemunho (Garrido, 1994). Atualmente, o psicólogo utiliza estratégias de avaliação psicológica, com objetivos bem definidos, para encontrar respostas para solução de problemas. A testagem pode ser um passo importante do processo, mas constitui apenas um dos recursos de avaliação (Cunha, 2000).

Esse histórico inicial reforça a aproximação da Psicologia e do Direito através da área criminal e a importância dada à avaliação psicológica. Porém, não era apenas no campo do Direito Penal que existia a demanda pelo trabalho dos psicólogos. Outro campo em ascensão até os dias atuais é a participação do psicólogo nos processos de Direito Civil. No estado de São Paulo, o psicólogo fez sua entrada informal no Tribunal 
de Justiça por meio de trabalhos voluntários com famílias carentes em 1979. A entrada oficial se deu em 1985, quando ocorreu o primeiro concurso público para admissão de psicólogos dentro de seus quadros (Shine, 1998).

Ainda dentro do Direito Civil, destaca-se o Direito da Infância e Juventude, área em que o psicólogo iniciou sua atuação no então denominado Juizado de Menores. Apesar das particularidades de cada estado brasileiro, a tarefa dos setores de psicologia era, basicamente, a perícia psicológica nos processos cíveis, de crime e, eventualmente, nos processos de adoção. Com a implantação do Estatuto da Criança e do Adolescente (ECA) Brasil (1990), em 1990, o Juizado de Menores passou a ser denominado Juizado da Infância e Juventude. 0 trabalho do psicólogo foi ampliado, envolvendo atividades na área pericial, acompanhamentos e aplicação das medidas de proteção ou medidas socioeducativas (Tabajaski, Gaiger \& Rodrigues, 1998). Essa expansão do campo de atuação do psicólogo gerou um aumento do número de profissionais em instituições judiciárias mediante a legalização dos cargos pelos concursos públicos. São exemplos a criação do cargo de psicólogo nos Tribunais de Justiça dos estados de Minas Gerais (1992), Rio Grande do Sul (1993) e Rio de Janeiro (1998) (Rovinski, 2002).

Outro dado histórico importante foi a criação do Núcleo de Atendimento à Família (NAF), em outubro de 1997, implantado no Foro Central de Porto Alegre e pioneiro na justiça brasileira. O trabalho objetiva oferecer a casais e famílias com dificuldades de resolver seus conflitos um espaço terapêutico que os auxilie a assumir o controle sobre suas vidas, colaborando, assim, para a celeridade do Sistema Judiciário (Silva \& Polanczyk, 1998).

Vale observar ainda que, com o propósito de acompanhar as mudanças legais e adequar as instituições de atendimento a crianças e adolescentes às diretrizes presentes no ECA, fez-se necessário o reordenamento institucional dessas entidades em todo o país. A extinta Fundação Estadual do Bem-Estar do Menor (FEBEM) mesclava, em uma mesma instituição, crianças e adolescentes vítimas de violência, maus tratos, negligência, abuso sexual e abandono com jovens autores de atos infracionais (http://www.sjds.rs.gov.br). Pela Lei 11.800/02 foram criadas duas fundações: a
Fundação de Atendimento Socioeducativo (FASE), responsável pela execução das medidas socioeducativas, e a Fundação de Proteção Especial (FPE), responsável pela execução das medidas de proteção. O surgimento dessas fundações se deu inicialmente no estado do Rio Grande do Sul. Elas são a consolidação do processo de adaptação aos preceitos regidos pelo ECA, iniciado nos anos 1990.

Diante do exposto, percebe-se um histórico inicial da aproximação da Psicologia e do Direito atrelado a questões envolvendo crime e também os direitos da criança e do adolescente. Contudo, nos últimos dez anos a demanda pelo trabalho do psicólogo em áreas como Direito da Família e Direito do Trabalho vem tomando força. Além desses campos, outras possibilidades de participação do psicólogo em questões judiciais vêm surgindo, as quais serão apresentadas e discutidas na segunda parte deste artigo.

Em relação à área acadêmica, cabe citar que a Universidade do Estado do Rio de Janeiro foi pioneira em relação à Psicologia Jurídica. Foi criada, em 1980, uma área de concentração dentro do curso de especialização em Psicologia Clínica, denominada "Psicodiagnóstico para Fins Jurídicos". Seis anos mais tarde, passou por uma reformulação e tornou-se um curso independente do Departamento de Clínica, fazendo parte do Departamento de Psicologia Social (Altoé, 2001). Atualmente, não são todos os cursos de Psicologia que oferecem a disciplina de Psicologia Jurídica. E, quando o fazem, normalmente é uma matéria opcional e com uma carga horária pequena. Já nos cursos de Direito, ainda que a carga horária também seja reduzida, a disciplina já se tornou de caráter compulsório.

Esses dados acarretam uma deficiência na formação acadêmica dos profissionais, o que exige o oferecimento, por parte das instituições judiciárias, de cursos de capacitação, treinamento e reciclagem. Os psicólogos sentem estar sempre "correndo atrás do prejuízo", uma vez que as discussões sempre giram ao redor de noções básicas com as quais o psicólogo deveria ter tomado contato antes de chegar à instituição (Anaf, 2000). Porém, essa realidade tem se modificado. Atualmente, são oferecidos cursos de pós-graduação em Psicologia Jurídica em universidades de estados brasileiros como Alagoas, Bahia, Ceará, Goiás, Minas Gerais, 
Paraíba, Pernambuco, Rio de Janeiro, Santa Catarina e São Paulo, o que revela a expansão da área no País.

Como pode ser evidenciado, o Direito e a Psicologia se aproximaram em razão da preocupação com a conduta humana. O momento histórico pelo qual a Psicologia passou fez com que, inicialmente, essa aproximação se desse por meio da realização de psicodiagnósticos, dos quais as instituições judiciárias passaram a se ocupar. Contudo, outras formas de atuação além da avaliação psicológica ganharam força, entre elas a implantação de medidas de proteção e socioeducativas e o encaminhamento e acompanhamento de crianças e/ou adolescentes. Observa-se que a avaliação psicológica ainda é a principal demanda dos operadores do Direito. Porém, outras atividades de intervenção, como acompanhamento e orientação, são igualmente importantes, como se verá na seção seguinte deste artigo. São áreas de atuação que devem coexistir, uma vez que seus objetivos são distintos, buscando atender a propósitos diferenciados, mas também complementares.

\section{Principais campos de atuação}

Na Psicologia Jurídica há uma predominância das atividades de confecções de laudos, pareceres e relatórios, pressupondo-se que compete à Psicologia uma atividade de cunho avaliativo e de subsídio aos magistrados. Cabe ressaltar que o psicólogo, ao concluir o processo da avaliação, pode recomendar soluções para os conflitos apresentados, mas jamais determinar os procedimentos jurídicos que deverão ser tomados. Ao juiz cabe a decisão judicial; não compete ao psicólogo incumbir-se desta tarefa. É preciso deixar clara esta distinção, reforçando a ideia de que o psicólogo não decide, apenas conclui a partir dos dados levantados mediante a avaliação e pode, assim, sugerir e/ou indicar possibilidades de solução da questão apresentada pelo litígio judicial.

Contudo, nem sempre o trabalho do psicólogo jurídico está ligado à questão da avaliação e consequente elaboração de documentos, conforme se apresenta a seguir. Os ramos do Direito que frequentemente demandam a participação do psicólogo são: Direito da Família, Direito da Criança e do Adolescente, Direito Civil, Direito Penal e Direito do Trabalho.
Cabe observar que o Direito de Família e o Direito da Criança e do Adolescente fazem parte do Direito Civil. Porém, como na prática as ações são ajuizadas em varas diferenciadas, optou-se por fazer essa divisão, por ser também didaticamente coerente.

- Psicólogo jurídico e o direito de família: destaca-se a participação dos psicólogos nos processos de separação e divórcio, disputa de guarda e regulamentação de visitas.

- Separação e divórcio: os processos de separação e divórcio que envolvem a participação do psicólogo são na sua maioria litigiosos, ou seja, são processos em que as partes não conseguiram acordar em relação às questões que um processo desse cunho envolve. Não são muito comuns os casos em que os cônjuges conseguem, de maneira racional, atingir o consenso para a separação. Isso implica resolver o conflito que está ou que ficou nas entrelinhas, nos meandros dos relacionamentos humanos, ou seja, romper com o vínculo afetivo-emocional (Silveira, 2006).

Portanto, o psicólogo pode atuar como mediador, nos casos em que os litigantes se disponham a tentar um acordo ou, quando o juiz não considerar viável a mediação, ao psicólogo pode ser solicitada uma avaliação de uma das partes ou do casal. Processos de separação e divórcio englobam partilha de bens, guarda de filhos, estabelecimento de pensão alimentícia e direito à visitação. Desta forma, seja como avaliador ou mediador, o psicólogo buscará os motivos que levaram o casal ao litígio e os conflitos subjacentes que impedem um acordo em relação aos aspectos citados. Nos casos em que julgar necessário, o psicólogo poderá, inclusive, sugerir encaminhamento para tratamento psicológico ou psiquiátrico da(s) parte(s).

- Regulamentação de visitas: conforme exposto acima, o direito à visitação é uma das questões a ser definida a partir do processo de separação ou divórcio. Contudo, após a decisão judicial podem surgir questões de ordem prática ou até mesmo novos conflitos que tornem necessário recorrer mais uma vez ao Judiciário, solicitando uma revisão nos dias e horários ou forma de visitas. Nesses casos, o psicólogo jurídico contribui por meio de avaliações com a família, objetivando esclarecer os conflitos e informar ao juiz a dinâmica presente nesta família, com sugestões das medidas que poderiam ser tomadas. O psicólogo pode, ainda, atuar 
como mediador, procurando apontar a interferência de conflitos intrapessoais na dinâmica interpessoal dos cônjuges, com o objetivo de produzir um acordo pautado na colaboração, de forma que a autonomia da vontade das partes seja preservada (Schabbel, 2005).

- Disputa de guarda: nos processos de separação ou divórcio é preciso definir qual dos ex-cônjuges deterá a guarda dos filhos. Em casos mais graves, podem ocorrer disputas judiciais pela guarda (Silva, 2006). Nesses casos, o juiz pode solicitar uma perícia psicológica para que se avalie qual dos genitores tem melhores condições de exercer esse direito. Além dos conhecimentos sobre avaliação, psicopatologia, psicologia do desenvolvimento e psicodinâmica do casal, assuntos atuais como a guarda compartilhada, falsas acusações de abuso sexual e síndrome de alienação parental podem estar envolvidos nesses processos. Portanto, é necessário que os psicólogos que atuam nessa área estudem esses temas, saibam seu funcionamento e busquem a melhor forma de investigá-los, de modo a realizar uma avaliação psicológica de qualidade.

Pais que colocam os interesses e vaidade pessoal acima do sofrimento que uma disputa judicial pode acarretar aos filhos, na tentativa de atingir ou magoar o ex-companheiro, revelam-se com problemas para exercer a parentalidade de forma madura e responsável (Castro, 2005). Portanto, nesses casos, a mediação não é uma prática comum, dado o alto nível de conflitos existentes entre os ex-cônjuges e que os fazem disputar seus filhos judicialmente.

- Psicólogo jurídico e o direito da criança e do adolescente: destaca-se o trabalho dos psicólogos junto aos processos de adoção e destituição de poder familiar e também o desenvolvimento e aplicação de medidas socioeducativas dos adolescentes autores de ato infracional.

- Adoção: os psicólogos participam do processo de adoção por meio de uma assessoria constante para as famílias adotivas, tanto antes quanto depois da colocação da criança. A equipe técnica dos Juizados da Infância e da Juventude deve saber recrutar candidatos para as crianças que precisam de uma família e ajudar os postulantes a se tornarem pais capazes de satisfazer às necessidades de um filho adotivo (Weber, 2004). A primeira tarefa de uma equipe de adoção é garantir que os candidatos estejam dentro dos limites das dispo- sições legais e a segunda é iniciar um programa de trabalho com os postulantes aceitos, elaborado especialmente para assessorar, informar e avaliar os interessados, e não apenas "selecionar" os mais aptos (Weber, 1997). Como a adoção é um vínculo irrevogável, o estudo psicossocial torna-se primordial para garantir o cumprimento da lei, prevenindo assim a negligência, o abuso, a rejeição ou a devolução.

Além do trabalho desenvolvido junto aos Juizados da Infância e Juventude, existe também o dos psicólogos que trabalham nas Fundações de Proteção Especial. Essas instituições têm como objetivo oferecer um cuidado especial capaz de minorar os efeitos da institucionalização, proporcionando às crianças e aos adolescentes abrigados uma vivência que se aproxima à realidade familiar. Os vínculos estabelecidos com os monitores que cuidam delas são facilitadores do vínculo posterior na adoção, uma vez que se estabelece e se mantém nos mesmos a capacidade de vincular-se afetivamente. As relações substitutas provisórias, representadas pelo acolhimento institucional que abriga os que aguardam uma possibilidade de inclusão em família substituta, são decisivas para o desenlace do processo de adoção (Albornoz, 2001).

- Destituição do poder familiar: o poder familiar é um direito concedido a ambos os pais, sem nenhuma distinção ou preferência, para que eles determinem a assistência, criação e educação dos filhos. Esse direito é assistido aos genitores, ainda que separados e a guarda conferida a apenas um dos dois. Porém, a legislação brasileira prevê casos em que esse direito pode ser suspenso, ou até mesmo destituído, de forma irrevogável. A partir desta determinação judicial, os pais perdem todos os direitos sobre o filho, que poderá ficar sob a tutela de uma família até a maioridade civil.

O papel do psicólogo nesses casos é fundamental. É preciso considerar que a decisão de separar uma criança de sua família é muito séria, pois desencadeia uma série de acontecimentos que afetarão, em maior ou menor grau, toda a sua vida futura. Independentemente da causa da remoção - doença, negligência, abandono, maus-tratos, abuso sexual, ineficiência ou morte dos pais - a transferência da responsabilidade para estranhos jamais deve ser feita sem muita reflexão (Cesca, 2004). 
- Adolescentes autores de atos infracionais: o Estatuto da Criança e do Adolescente prevê medidas socioeducativas que comportam aspectos de natureza coercitiva. São medidas punitivas no sentido de que responsabilizam socialmente os infratores, e possuem aspectos eminentemente educativos, no sentido da proteção integral, com oportunidade de acesso à formação e à informação. Os psicólogos que desenvolvem seu trabalho junto aos adolescentes infratores devem Ihes propiciar a superação de sua condição de exclusão, bem como a formação de valores positivos de participação na vida social. Sua operacionalização deve, prioritariamente, envolver a família e a comunidade com atividades que respeitem o princípio da não discriminação e não estigmatização, evitando rótulos que marquem os adolescentes e os exponham a situações vexatórias, além de impedi-los de superar as dificuldades na inclusão social.

Na Fundação de Apoio Socioeducativo de Porto Alegre (RS), colocou-se em prática um projeto pioneiro que utiliza soluções mais eficazes para responsabilizar e corrigir comportamentos considerados transgressores: a Justiça Restaurativa. Essa medida tem por objetivo tratar e julgar melhor as questões que levaram os jovens a cometerem um ato infracional, e tem como foco a reparação dos danos causados às pessoas e relacionamentos, ao invés de punir os transgressores. Através de um mediador, as vítimas e os jovens procuram dialogar para que eles se conscientizem dos erros que cometeram. Esse tipo de projeto tem o intuito de evitar que o adolescente volte a cometer crimes e que os danos causados às vítimas sejam minimizados (Jesus, 2005).

Psicólogo jurídico e o direito civil: o psicólogo atua nos processos em que são requeridas indenizações em virtude de danos psíquicos e também nos casos de interdição judicial.

- Dano psíquico: o dano psíquico pode ser definido como a sequela, na esfera emocional ou psicológica, de um fato particular traumatizante (Evangelista \& Menezes, 2000). Pode-se dizer que o dano está presente quando são gerados efeitos traumáticos na organização psíquica e/ou no repertório comportamental da vítima. Cabe ao psicólogo, de posse de seu referencial teórico e instrumental técnico, avaliar a real presença desse dano. Entretanto, o psicólogo deve estar atento a possíveis 488 manipulações dos sintomas, já que está em suas mãos a recomendação, ou não, de um ressarcimento financeiro (Rovinski, 2005).

- Interdição: a interdição refere-se à incapacidade de exercício por si mesmo dos atos da vida civil. Uma das possibilidades de interdição previstas pelo código civil são os casos em que, por enfermidade ou deficiência mental, os sujeitos de direito não tenham o necessário discernimento para a prática dos atos da vida civil. Nesses casos, compete ao psicólogo nomeado perito pelo juiz realizar avaliação que comprove ou não tal enfermidade mental. Àjustiça interessa saber se a doença mental de que o paciente é portador o torna incapaz de reger sua pessoa e seus bens (Monteiro, 1999).

As questões levantadas em um processo de interdição incluem a validade, nulidade ou anulabilidade de negócios jurídicos, testamentos e casamentos. Além dessas, ficam prejudicadas a contração de deveres e aquisição de direitos, a aptidão para o trabalho, a capacidade de testemunhar e a possibilidade de ele próprio assumir tutela ou curatela de incapaz e exercer o poder familiar (Taborda, Chalub \& Abdalla-Filho, 2004).

- Psicólogo jurídico e o direito penal: o psicólogo pode ser solicitado a atuar como perito para averiguação de periculosidade, das condições de discernimento ou sanidade mental das partes em litígio ou em julgamento (Arantes, 2004). Portanto, destaca-se o papel dos psicólogos junto ao Sistema Penitenciário e aos Institutos Psiquiátricos Forenses.

A criação da Lei de Execução Penal (LEP), em 1984, foi um marco no trabalho dos psicólogos no sistema prisional, pois a partir dela o cargo de psicólogo passou a existir oficialmente (Carvalho, 2004). A Lei 10.792/2003 trouxe mudanças à LEP, uma vez que extinguiu o exame criminológico feito para instruir pedidos de benefícios e o parecer da Comissão Técnica de Classificação Brasil (2003). Para a concessão de benefícios legais, as únicas exigências previstas são o lapso de tempo já cumprido e a boa conduta. No entanto, há uma pressão por parte do Ministério Público e Poder Judiciário pela continuidade das avaliações técnicas. No estado de São Paulo, após as rebeliões ocorridas no sistema penitenciário, as avaliações técnicas estão voltando a ser uma exigência para a concessão dos benefícios legais (Sá, 2007).

As avaliações psicológicas individualizadas, previstas em lei, são inviáveis nos presídios brasileiros 
em razão das superpopulações existentes. Pelo mesmo motivo, proporcionar um "tratamento penal" aos apenados ou estabelecer outro tipo de relações institucionais com os demais funcionários, internos e/ou seus familiares são tarefas difíceis para os psicólogos que trabalham junto ao sistema carcerário (Kolker, 2004).

Existe ainda o trabalho dos psicólogos junto aos doentes mentais que cometeram algum delito. Esses sujeitos recebem medida de segurança, decretada pelo juiz, e são encaminhados para Institutos Psiquiátricos Forenses (IPF). Além de abrigar esses doentes mentais, os IPF são responsáveis pela realização de perícias oficiais na área criminal e pelo atendimento psiquiátrico à rede penitenciária. Atualmente existem no Brasil 28 instituições psiquiátricas forenses e cerca de 4 mil internos (Piccinini, 2006).

No Rio Grande do Sul, o Instituto Psiquiátrico Forense Maurício Cardoso (IPFMC) foi o segundo fundado no País, em 1924. O trabalho do psicólogo nesse instituto teve início em 1966, através do estágio curricular de psicopatologia. Inicialmente as atividades da Psicologia eram subordinadas à Medicina, pois havia a necessidade de prescrição médica para os pacientes psicóticos. Além disso, os laudos psiquiátricos elaborados não eram assinados pelos psicólogos, devido a um dispositivo legal que atribuía a competência e a responsabilidade desses laudos ao psiquiatra forense (Modena, 2007). Com o passar dos anos houve ampliação do atendimento multidisciplinar, que passou a reunir as diferentes habilidades técnicas em prol de uma prestação de serviço com maior qualidade aos pacientes. Assim, o Setor de Psicologia foi alcançando sua independência e autonomia dentro dos IPF.

Psicólogo jurídico e o direito do trabalho: o psicólogo pode atuar como perito em processos trabalhistas. A perícia a ser realizada nesses casos serve como uma vistoria para avaliar o nexo entre as condições de trabalho e a repercussão na saúde mental do indivíduo. Na maioria das vezes, são solicitadas verificações de possíveis danos psicológicos supostamente causados por acidentes e doenças relacionadas ao trabalho, casos de afastamento e aposentadoria por sofrimento psicológico. Cabe ao psicólogo a elaboração de um laudo, no qual irá traduzir, com suas habilidades e conhecimento, a natureza dos processos psicológicos sob investigação (Cruz\& Maciel, 2005).

\section{Outros campos de atuação}

Vitimologia: objetiva a avaliação do comportamento e da personalidade da vítima. Cabe ao psicólogo atuante nessa área traçar o perfil e compreender as reações das vítimas perante a infração penal. A intenção é averiguar se a prática do crime foi estimulada pela atitude da vítima, o que pode denotar uma cumplicidade passiva ou ativa para com o criminoso. Para tanto, a análise é feita desde a ocorrência até as consequências do crime (Brega Filho, 2004). Além disso, a vitimologia dedica-se também à aplicação de medidas preventivas e à prestação de assistência às vítimas, visando, assim, à reparação de danos causados pelo delito.

Psicologia do testemunho: os psicólogos podem ser solicitados a avaliar a veracidade dos depoimentos de testemunhas e suspeitos, de forma a colaborar com os operadores da justiça. O chamado fenômeno das falsas memórias tem assumido um papel muito importante na área da Psicologia do Testemunho. Hoje, sabe-se que o ser humano é capaz de armazenar e recordar informações que não ocorreram. As falsas memórias podem resultar da repetição de informações consistentes e inconsistentes no depoimento de testemunhas sobre o mesmo evento. É preciso desenvolver pesquisas na área que possam contribuir para a elucidação dos mecanismos responsáveis pelas falsas memórias e, assim, auxiliar o aprimoramento de técnicas para avaliação de testemunhos (Stein, 2000).

Uma área recente e relacionada à Psicologia do Testemunho que vem ganhando espaço é o Depoimento sem Dano, que objetiva proteger psicologicamente crianças e adolescentes vítimas de abusos sexuais e outras infrações penais que deixam graves sequelas no âmbito da estrutura da personalidade. Esse projeto foi criado no Segundo Juizado da Infância e Juventude de Porto Alegre, em razão das dificuldades enfrentadas pela justiça na tomada de depoimentos de crianças e adolescentes (Cezar, 2007).

A fim de atingir tais objetivos, é importante que o técnico entrevistador - assistente social ou psicólogo - possua habilidade em ouvir, demonstre paciência, empatia, disposição para o acolhimento e capacidade de deixar o depoente à vontade durante a audiência. 0 técnico deve, ainda, conhecer acerca da dinâmica do 
abuso e, preferencialmente, possuir experiência em situações de perícia, o que facilita a compreensão e interação de todos os envolvidos no ato judicial (Cezar, 2007). Desta forma, a inserção de uma equipe psicossocial no âmbito da justiça respeita e preserva o estado emocional da vítima, permitindo, assim, um processo menos oneroso e mais justo para o caso.

\section{Considerações Finais}

Este artigo buscou apontar o histórico da Psicologia Jurídica, algumas questões referentes à formação acadêmica nessa área e os principais campos de atuação. Diante do exposto, é possível concluir que esse ramo da Psicologia é muito recente, especialmente na área científica. As referências utilizadas para construir esse material reforçam a dificuldade de encontrar textos relacionados ao assunto, especialmente artigos científicos. As deficiências na formação decorrem, em parte, do rápido desenvolvimento das relações entre Psicologia e Direito e o despreparo para lidar com os avanços e as novas áreas de atuação que surgem a cada dia.

Ao analisar os campos de atuação do psicólogo jurídico, percebe-se um predomínio da atuação desses profissionais enquanto avaliadores. A elaboração de psicodiagnósticos, presente desde o surgimento da Psicologia Jurídica, permanece como um forte campo de exercício profissional. Contudo, a demanda por acompanhamentos, orientações familiares, participações em políticas de cidadania, combate à violência, participação em audiências, entre outros, tem crescido enormemente. Esse fato amplia a inserção do psicólogo no âmbito jurídico, ao mesmo tempo em que exige uma constante atualização dos profissionais envolvidos na área. O psicólogo não pode deixar de realizar psicodiagnósticos, âmbito de sua prática privativa. Entretanto, deve estar disposto a enfrentar as novas possibilidades de trabalho que vêm surgindo, ampliando seus horizontes para novos desafios que se apresentam.

Destaca-se ainda a necessidade de ampliar o espaço para discussão acerca da Psicologia Jurídica no ambiente acadêmico, mediante a criação de disciplinas e promoção de encontros nos quais se busque suprir a carência existente nos currículos dos cursos de Psicologia. Ademais, é preciso ampliar a área de pesquisa, de forma a produzir obras científicas que contemplem os diferentes campos em que a Psicologia Jurídica tem passado a atuar e contribuir. A partir do momento em que as pesquisas realizadas comprovem a importância do trabalho do psicólogo junto às instituições judiciárias, a inserção e valorização do trabalho deste profissional ficam facilitadas e fortalecidas.

Por fim, destaca-se a necessidade de conhecer determinadas terminologias da área jurídica e a importância de um trabalho interdisciplinar, junto a advogados, juízes, promotores, assistentes sociais e sociólogos. Eis o grande desafio da psicologia jurídica: não ficar limitada aos conhecimentos advindos da ciência psicológica e trocar conhecimentos com ciências afins, buscando redimensionar a compreensão do agir humano, considerando os aspectos legais, afetivos e comportamentais.

\section{Referências}

Albornoz, A. C. G. (2001). Adoção: aspectos psicológicos. Psico, 32 (2), 195-206.

Altoé, S. E. (2001). Atualidade da psicologia jurídica. Psibrasil Revista de Pesquisadores da Psicologia no Brasil, 2. Recuperado em agosto 2006, disponível em www.estig. ipbeja.pt/ ac_direito/psicologiarevistasest.html

Anaf, C. (2000). Formação em psicologia jurídica. In Universidade Presbiteriana Mackenzie (Ed.), Anais do 30 Congresso Ibero-Americano de Psicologia Jurídica (pp. 91-93). São Paulo.

Arantes, E. M. M. (2004). Pensando a psicologia aplicada à justiça. In H. S. Gonçalves \& E. P. Brandão. Psicologia jurídica no Brasil (pp.15-49). Rio de Janeiro: NAU Editora.

Balu, T. H. (1984). The psychologist as expert witness. New York: John Wiley \& Sons.

Brasil. (1990). Estatuto da criança e do adolescente. Lei $n^{\circ}$ 8.069/90. Recuperado em junho, 2007, disponível em http://www.planalto.gov.br/ccivil/Leis/L8069.htm

Brasil. (1984). Lei de Execução Penal. Lei n 7.210/84. Recuperado em agosto, 2007, disponível em http://www. planalto.gov.br/ccivil/LEIS/L7210.htm

Brasil. Lei $n^{\circ}$ 10.792/2003. Recuperado em agosto, 2007, disponível em http://www.planalto.gov.br/CCIVIL/LEIS/ 2003/L10.792.htm

Brega Filho, V. (2004). A reparação do dano no Direito Penal brasileiro. Perspectivas. Jus Navegandi, 318. Recuperado em fevereiro, 2007, disponível em http://jus2.uol.com.br/ Doutrina/texto.asp?id=5242 
Brito, L. M. T. (2005). Reflexões em torno da psicologia jurídica. In R. M. Cruz, S. K. Maciel \& D. C Ramirez. O trabalho do psicólogo no campo jurídico (pp.9-17). São Paulo: Casa do Psicólogo.

Carvalho, S. (2004). O papel da perícia psicológica na execução penal. In H. S. Gonçalves \& E. P. Brandão. Psicologia jurídica no Brasil (pp.141-155). Rio de Janeiro: NAU Editora.

Castro, L. R. F. (2005). Disputa de guarda e visitas: no interesse dos pais ou dos filhos? São Paulo: Casa do Psicólogo.

Cesca, T. (2004). O lugar da psicologia forense na violência intrafamiliar. Psicologia para América Latina, 2. Recuperado em junho, 2007, disponível em http://pepsic.bvspsi.org.br/scielo.php?script=sci_arttext\&pid=\$1870350X2004000200006\&lng=pt\&nrm $=$ iso

Cezar, J. A. D. (2007). Depoimento sem dano: uma alternative para inquirir crianças e adolescents nos processos judiciais. Porto Alegre: Livraria do Advogado.

Cruz, R. M., \& Maciel, S. K. (2005). Perícia de danos psicológicos em acidentes de trabalho. Estudos e Pesquisas em Psicologia, 5 (2), 120-129.

Cunha, J. A. (1993). Fundamentos do psicodiagnóstico. In J. A. Cunha. Psicodiagnóstico-R. Porto Alegre: Artes Médicas.

Cunha, J. A. (2000). Psicodiagnóstico - V. Porto Alegre: Artes Médicas.

Evangelista, R., \& Menezes, I. V. (2000). Avaliação do dano psicológico em perícias acidentárias. Revista IMESC, 2, 45-50. Recuperado em março, 2007, disponível em http://www.imesc.sp.gov.br/pdf/art2rev2.pdf

Fernandes, M. A. (1998). O trabalho do psicólogo junto ao sistema penitenciário: tratamento penal. Aletheia, 7, 41-49.

Garrido, E. M. (1994). Relaciones entre la psicologia y la ley. In R. Sobral, R. Arece \& A. L. Prieto. Manual de psicologia jurídica. Barcelona: Paidós.

Gromth-Marnat, G. (1999). Handbook of psychological assessment (3rd ed.) New York: Wiley \& Sons.

Jesus, D. E. (2005). Justiça restaurativa no Brasil. Jus Navigandi, 9, 819. Recuperado em agosto, 2007, disponível em http://jus2.uol.com.br/doutrina/texto.asp?id=7359

Jesus, F. (2001). Breve histórico da psicologia jurídica. In F. Jesus. Psicologia aplicada à justiça (pp. 27-30). Goiânia: AB Editora.

Kolker, T. (2004). A atuação dos psicólogos no sistema penal. In H. S. Gonçalves \& E. P. Brandão. Psicologia jurídica no Brasil (pp.157-204). Rio de Janeiro: NAU Editora.

Modena, S. L. (2007). A importância da avaliação psicológica na definição de inimputabilidade. Monografia não-publicada, Programa de Pós-Graduação em Psicologia, Universidade Federal do Rio Grande do Sul, Porto Alegre.

Monteiro, W. B. (1999). Da Curatela. In W. B. Monteiro. Curso de direito civil: direito de família (Vol. 2, pp.325-335). São Paulo: Saraiva.
Pavon, F. M. (1997). Etapas históricas de la psicologia jurídica. In F. M. Pavon. Psicologia jurídica (pp.15-21). Quito, Equador: Artes Gráficas CQ.

Piccinini, W. J. Resenha do livro intitulado Psiquiatria forense: 80 anos de prática institucional (2006). Revista de Psiquiatria do Rio Grande do Sul, 28 (3) 361-362. Recuperado em agosto, 2007, disponível em http://www.scielo.br/ scielo.php? script=sci_arttext\&pid=S0101-8108200 $6000300018 \& \mathrm{lng}=\mathrm{en} \& \mathrm{nrm}=$ iso

Rovinski, S. L. R. (1998). A perícia psicológica. Aletheia, 7, 55-63.

Rovinski, S. L. R. (2002). La psicologia jurídica em Brasil. In J. Urra. Tratado de psicología forense (pp.661-665). Madrid: Siglo Veintiuno de España Editores.

Rovinski, S. L. R. (2005). A avaliação do dano psíquico em mulheres vítimas de violência. In S. Shine. Avaliação psicológica elei: adoção, vitimização, separação conjugal, dano psíquico e outros temas (pp.175-189). São Paulo: Casa do Psicólogo.

Sá, A. A. (2007). As avaliações técnicas dos encarcerados. In A. A. Sá. Criminologia clínica e psicologia criminal (pp.188-208). São Paulo: Editora Revista dos Tribunais.

Schabbel, C. (2005). Relações familiares na separação conjugal: contribuições da mediação. Psicologia Teoria e Prática, 7 (1), 13-20.

Shine, S. (1998). Contribuições da psicologia para a justiça nas varas de família. Aletheia, 7, 93-99.

Silva, D. M. P. (2006). Psicologia jurídica no processo civil brasileiro. São Paulo: Casa do Psicólogo.

Silva, M. C. S., \& Polanczyk, T. M. V. (1998). Implantação de um núcleo de atendimento à família no judiciário. Aletheia, 7, 65-73.

Silveira, M. V. (2006). O litígio nas separações. In I. M. C. C. Souza. Casamento uma escuta além do judiciário (pp.281-290). Florianópolis: VoxLegem.

Souza, F. J. (1998). O campo de trabalho da psicologia jurídica. Aletheia, 7, 5-8.

Stein, L. M. (2000). Falsas memórias em depoimentos de testemunhas. In Anais do $3^{\circ}$ Congresso lbero-americano de Psicologia Jurídica (pp.213-216). São Paulo: Universidade Presbiteriana MacKenzie.

Tabajaski, B., Gaiger, M., \& Rodrigues, R. B. (1998). O trabalho do psicólogo no juizado da infância e da juventude de Porto Alegre/RS. Aletheia, 7, 9-18.

Taborda, J. G. V., Chalub, M., \& Abdalla-Filho, E. (2004). Psiquiatria forense. Porto Alegre: Artmed.

Weber, L. N. D. (1997). Critérios de seleção de famílias adotivas: em discussão. Interação, 1 (1), 123-137.

Weber, L. N. D. (2004). O psicólogo e as práticas de adoção. In H. S. Gonçalves \& E. P. Brandão. Psicologia jurídica no Brasil (pp.99-140). Rio de Janeiro: NAU Editora.

Recebido em: 5/11/2007

Versão final reapresentada em: 7/7/2008

Aprovado em: 29/9/2008 